УДК 674.812-419

\title{
УТИЛИЗАЦИЯ РАЗЛИЧНОГО ВИДА ДРЕВЕСНЫХ ОТХОДОВ НА ПРЕДПРИЯТИЯХ ЖЕЛЕЗНОЙ ДОРОГИ
}

\author{
Чистова Наталья Геральдовна \\ д. т. н., профессор \\ Воробьева Оксана Евгеньевна \\ Лыжина Маргарита Сергеевна \\ Савастеева Мария Сергеевна \\ ФГБОУ ВО «Красноярский институт \\ железнодорожного транспорта» - филиал ИрГУПС в г.Красноярск
}

Аннотация: В настоящей работе ставилась задача проанализировать проблему утилизации различных видов древесных отходов на предприятиях железной дороги. Исследования и выполненный в работе анализ железнодорожных предприятий Красноярского края и положения комплексной переработки растительного сырья на них, направлены на поиск решений по улучшению комплексной переработки и утилизации древесных отходов.

Ключевые слова: утилизация, древесные отходы, брикетирование, гранулирование, переработка, ресурсы.

\section{UTILIZATION OF VARIOUS TYPES OF WOOD WASTE AT RAILWAY ENTERPRISES}

\author{
Chistova Natalia Geraldovna \\ Vorobyova Oksana Evgenievna \\ Lyzhina Margarita Sergeevna \\ Savateeva Maria Sergeevna
}

\begin{abstract}
In this paper, the task was to analyze the problem of utilization of various types of wood waste at railway enterprises. Research and analysis of railway enterprises of the Krasnoyarsk territory and the situation of integrated processing of plant raw materials on them are aimed at finding solutions to improve the integrated processing and disposal of wood waste.
\end{abstract}

Key words: recycling, wood waste, briquetting, granulation, recycling, resources. 
На современном этапе развития транспортных предприятий Красноярского края имеется много проблем одна из, которых переработка и утилизация отходов производства, в том числе растительного происхождения.

Отсутствие широкомасштабного применения современных малоотходных технологий на предприятиях приводит не только к безвозвратным потерям высокотехнологичного и экономически чистого природного материала, но и способствует ухудшению состояния окружающей среды.

В настоящее время при существующем уровне техники и технологий древесное сырье используется неэффективно. Так, например, в готовых изделиях из древесины используется только $45-50 \%$ общего объёма заготавливаемого сырья, а остальная часть превращается в отходы, которые в основном используются в дальнейшем как топливо или вывозятся в отвалы.

В Красноярском институте железнодорожного транспорта ведущими преподавателями совместно со студентами активно рассматриваются вопросы и проводятся исследования комплексной переработки растительного сырья, экологии и безопасности жизни деятельности, в том числе и вопросы об утилизации отходов образующиеся вдоль железнодорожного полотна.

На объектах транспортной инфраструктуры (ОТИ) РЖД и предприятиях Красноярского края практически не решаются вопросы комплексной переработки древесины. В процессе исследований установлено, что ежегодно в процессе деятельности предприятий образуется более 250 тыс. м $^{3}$ различных видов отходов растительного происхождения, большая часть которых просто сжигается или закапывается, часть отходов реализуется на переработку потребителям.

Самая существенная часть отходов это макулатура, лесосечные отходы, опилки, кусковые древесные отходы и др. Чаще всего предприятиям приходиться нанимать транспорт и вывозить отходы, в отвал на захоронение, некоторые предприятия сжигают их прямо на своей территории. Во всех этих случаях предприятия несут ощутимые затраты и в том числе противопожарные и экологические платежи и штрафы [2, с. 7].

На наш взгляд ОТИ РЖД и предприятиями Красноярского края более целесообразно подготавливать и перерабатывать различные отходы растительного сырья собственными силами.

Например, на наш взгляд, одним из перспективных направлений в переработке древесных отходов является их гранулирование и брикетирование с последующей их реализацией. Древесные гранулы представляют собой 
прессованные цилиндры однородной формы, полученные из естественных отходов древесины - опилок, сучьев. Обычно их производят диаметром 6-8 мм и длиной 10-30 мм, путем прессования под высоким давлением без применения химических добавок. Удельная теплота сгорания гранул составляет 4,9 кВтч/кг. Например, при сжигании 1000кг древесных гранул выделяется столько же энергии как при сжигании 1600кг древесины или 500 литров дизельного топлива.

Второй способ переработки отходов - это брикетирование. Брикеты-это плотные куски, полученные из сыпучей древесины путем прессования ее со связующими или без них. Более широко распространена технология брикетирования без применения связующих, т. к. при этом получают экологически чистый продукт. Теплотворная способность брикетов 4000ккал/кг.

Такой вид переработки на наш взгляд представляет собой безопасное с экологической точки зрения, чистое топливо с высокой теплотворной способностью без значительных капитальных вложений, предназначенное для использования в автоматизированных топочных устройствах. Так, из-за своей высокой плотности гранулы и брикеты нуждаются в значительно меньших складских площадях, чем остальные горючие материалы биологического происхождения, что позволяет хранить весь сезонный запас топлива в одном здании. В случае складирования неупакованных гранул необходимо обратить внимание на то, что хранилище требуется защитить от влажности и от выброса пыли. Хотя процент поглощения влаги брикетами гораздо ниже, чем у цельной древесины.

На сегодняшний день производство гранул и брикетов - одно из самых перспективных направлений в комплексной переработке растительного сырья. Продукты такого характера решат проблему нехватки топлива, как в нашей стране, так и в других странах. По мнению многих ученых, именно использование биотоплива приведет к развитию устойчивой, экологически благоприятной энергетики [1, с. 21].

Анализ всех нюансов рассматриваемого в работе вопроса показал, что отечественные установки по производству гранул предпочтительнее зарубежным аналогам, так как их окупаемость в несколько раз ниже, чем у зарубежных аналогов, a, следовательно, и себестоимость гранул будет значительно ниже [1, с. 32].

Объем поставок отечественного оборудования на внутренний рынок пока незначительный, но он непрерывно будет, увеличивается, на наш взгляд, это 
неизбежно. Преимущества гранул и брикетов в сравнении с другими видами топлива можно условно разделить на экологические и экономические. Экологические очевидны всем, а экономические до последнего времени не принимали в расчет. Этот вид биотоплива считается нейтральными относительно выделения двуокиси углерода; это значит, что, то количество, которое выделятся во время горения, было предварительно впитано деревом в период роста. Напротив, при использовании горючих материалов ископаемого происхождения в воздух выделяется углекислота, накопившаяся за многие миллионы лет. Это выделение вызывает повышение уровня $\mathrm{CO}_{2}$ в атмосфере, что является основной причиной парникового эффекта. Для наглядности приведем простой пример: при переводе отопления в коттедже с дизельного топлива на гранулы выделение $\mathrm{CO}_{2}$ уменьшится на 4,8 т/год. В случае перехода с газа на гранулы эта величина составит 2,5 т/год. Кроме уменьшения выделения углекислоты, использование древесных гранул, снижает также выделение серной кислоты. Именно соединение в атмосфере $\mathrm{CO}_{2}$ с водой является причиной выпадения кислотных дождей, которые крайне негативно воздействуют на природный баланс, приводя к вымиранию лесов. Наряду с этим транспортировать древесные гранулы в виду их большого коэффициента полнодревесности, чем у крупногабаритной древесины значительно выгодней.

Не менее важный фактор - отсутствие риска загрязнения окружающей среды при перевозке гранул и брикетов. Это относится как к автомобильным, железнодорожным и морским авариям при транспортировке нефтематериалов, так и к бытовым взрывам газа. Если же сравнивать количество несгораемых остатков при сжигании, то гранулы при невысокой теплоемкости производят меньше выделений угарного газа (СО) и золы, чем другие виды горючего дрова и уголь. Малое содержание золы $(<1,5 \%)$ вкупе с невысокой по сравнению с другими горючими биоматериалами влажностью (12\%) влекут за собой повышения удельной теплоты сгорания. Золу можно так же использовать в качестве удобрения Экономическая сторона производства гранул и брикетов также должна приниматься в расчет. Сегодня, когда от стадии разговоров и проектов перешли к стадии конкретных дел, производство этого вида топлива означает создание большого количества рабочих мест в промышленности, торговле, а также в области сельского и лесного хозяйства. Второй немаловажный фактор - стабильные и конкурентоспособные цены. Себестоимость гранул и брикетов совершенно не зависит от колебаний цен и на газ и нефть. Использование этих энергоносителей в условиях все 
возрастающего контроля за состоянием окружающей среды и распространение экологических налогов и сборов не может не сокращаться. Не следует забывать и о частых кризисах на нефтяном рынке.

Таким образом можно отметить следующее:

Bo-nepвыx, древесные гранулы, как производные от древесины, являются возобновляемым топливом. А такое топливо, как нефть или газ, будут с каждым годом расти в цене и вскоре закончатся.

Bo-вmopblx, древесные гранулы обладают высокой энергоконцентрацией при незначительном занимаемом объеме. Кроме того, гранулы могут перемещаться в автоматических печах и могут вдуваться на склад и транспорт.

$\boldsymbol{B}$-mpembux, пепел может использоваться как удобрение. Зола составляет до 1\% от массы топлива. Пепел убирается в современных печах и котлах раз в два года.

B-четвертых, так как гранулы обладают высокой насыпной массой, требуется не много места для складирования. Для отопления гранулами дома

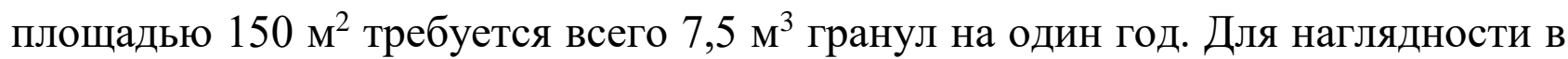
таблице 1 приведены Сравнительные характеристики различных видов топлива.

Таблица 1

Сравнительные характеристики различных видов топлива

\section{Сравнительные характеристики видов топлива}

\begin{tabular}{|l|c|c|c|c|}
\hline \multicolumn{1}{|c|}{ Вид топлива } & $\begin{array}{c}\text { Теплота } \\
\text { сгорания } \\
\text { МДж/кг }\end{array}$ & \% серы & \% золы & $\begin{array}{c}\text { Углекислый } \\
\text { газ } \\
\text { кг/ГДж }\end{array}$ \\
\hline Каменный уголь & $15-25$ & $1-3$ & $10-35$ & 60 \\
\hline Двигательное топливо & 42,5 & 0,2 & 1 & 78 \\
\hline Мазут & 42 & 1,2 & 1,5 & 78 \\
\hline Щепа древесная & 10 & 0 & 2 & 0 \\
\hline Гранулы древесные & 17,5 & 0,1 & 1 & 0 \\
\hline Гранулы торфяные & 10 & 0 & 20 & 70 \\
\hline Гранулы из соломы & 14,5 & 0,2 & 4 & 0 \\
\hline Природный газ & $35-38$ & 0 & 0 & 57 \\
\hline
\end{tabular}


Потенциальными покупателями могут выступать жители частного сектора и владельцы производств, где установлены твердотопливные котлы, камины. Можно наладить сбыт продукции предприятиям отраслей сельского хозяйства, строительства, мебельной промышленности.

Сколько можно зарабатывать на переработке древесных отходов: если взять к расчету среднюю производительность линии по производству гранул $1 \ldots 2$ т/час, т.е. 7..15 тыс. тонн в год, то можно зарабатывать почти миллион рублей в месяц. При инвестициях 11,6 млн. руб. срок окупаемости = полтора года, при инвестициях 13 млн. руб. = 10 месяцев. Комплект оборудования можно купить за 3...7 млн. руб. И если не нужно строить здания и сооружения (забор и т.п.) - окупаемость - может быть даже 6 месяцев.

На основе вышесказанного можно сделать следующие выводы, что производство гранул и брикетов с течением времени будет только возрастать благодаря снижению в будущем цен на их производство и транспортировку, а также из-за увеличения стоимости нефтепродуктов.

Проанализировав работу железнодорожных предприятий Красноярского края и положения комплексной переработки растительных отходов на них, можно сделать вывод, что необходимо искать пути и направления улучшения комплексной переработки и утилизации древесных отходов. И как одно из перспективных направлений для решения данного вопроса необходимо внедрять и расширять технологии по брикетированию и гранулированию древесных отходов, которые успешно внедряются и работают за рубежом, так и в России.

\section{Список литературы}

1. Петрушева Н.А, Чистова Н.Г, Нигматулина М.М. К вопросу об утилизации отходов производства ДВП мокрым способом. Сборник: Природоресурсный потенциал, экологии и устойчивости развития ресурсов России февраль 2005г.

2. Секиров Р. Перспективный вид топлива // Дерево.RU. - 2004. N 3(21). - C.20-21.

(C) Н.Г. Чистова, О.Е. Воробьева, М.С. Лыжина, М.С. Савастеева, 2020 